\title{
ROLE OF TUMOR MARKERS IN THE DIAGNOSIS OF MALIGNANT PLEURAL EFFUSIONS
}

\section{Subhakar Kandi*}

Ajay Kumar P

\section{Shravika Reddy} Kandi
Department of Pulmonary Medicine, Osmania Medical College, Hyderabad, India. * Corresponding Author

Department of Pulmonary Medicine, Osmania Medical College, Hyderabad, India.

ABSTRACT As an aid in the differential diagnosis of oxidative pleural effusions tumor markers were investigated. We carcinomatous pleural effusions and of ten patients with tuberculous pleurisy and other causes because we have frequently found those diseases to be associated with exudative pleuritis. CEA and CA 15-3 were significantly higher in carcinomatous pleural fluids than in tuberculous fluids ( $p$ value of 0.0287), therefore combined assay of CEA and CA 15-3 may be useful in distinguishing pleural effusions due to malignancies from those of tuberculous origin.

KEYWORDS : Carciniembrionic antigen, CA 15-3, carcinomatous pleural effusion, Tuberculous pleural effusion

\section{INTRODUCTION}

Pleural effusions are common diagnostic problem in clinical practice. Common etiologies of exudative pleural effusions in our experience are carcinoma and tuberculosis. Even with all invasive investigations about $10-20 \%$ of patients will remain with out diagnosis. [1,2] In such cases determination of various tumor markers in the pleural fluid may be helpful in the differential diagnosis. [3]

Carcinogen Embryonic Antigen (CEA) is a cell surface $200 \mathrm{kd}$ glycoprotein antigen that can be found in normal tissues and elevations of CEA are observed in more than $30 \%$ of patients with carcinoma of lung, liver, pancreas, breast, colon, head and neck, cervix and prostate. [4] The other markers that has caused most interest and for which there is most information is CA 15-3 a 300-450 kd glycoprotein. The antigen is identified by two antibodies (i.e., DF3 and $111 \mathrm{DB}$ ) one from human milk fat globules and other from membranes of a human metastatic breast carcinoma cell line $[5,6]$

We measured CEA and CA 15-3 in carcinomatous and tuberculous pleural effusions and attempted to discriminate between the two groups.

\section{MATERIALS AND METHODS}

We prospectively studied pleural fluid samples of the patients, who were diagnosed as malignant pleurisy or tuberculous pleurisy in Government General and Chest Hospital, which were frozen and stored at $-20 \mathrm{C}$ until assayed. Among these 33 samples from carcinomatous pleurisy, which met one of the following criteria a) demonstration of malignant cells at cytological examination or in a biopsy specimen or b) histologically proven primary malignancy with exclusion of any other cause known to be associated with pleural effusions. Ten samples from tuberculosis pleurisy, which was confirmed by bacteriological study.

Among the carcinomatous pleurisy 22 were primary lung carcinomas, which includes 14 adenocarcinoma, seven squamous cell carcinoma and one mesothelioma. Two cases of metastatic carcinoma, two cases of breast carcinoma, two cases of lymphoma and five cases of premalignant effusions.

Determination of tumor markers was performed by radio immune assay. The cut off values chosen for CEA and CA $15-3$ were $8 \mathrm{ng} / \mathrm{ml}$ and $42 \mathrm{U} / \mathrm{ml}$ respectively, above this values are considered as positive. Incidence of positive tumor markers in carcinomatous and tuberculous pleural effusions are enumerated in Table 1.

\section{Ethical approval}

This study was approved by Government General and Chest Hospital ethical committee. Individual patient's well informed and written consent was taken.

\section{RESULTS}

Among the 33 carcinomatous samples 21 were males, with age ranged from 15 to 88 years with a mean age of $53.7 \pm 14$ years, and those with ten tuberculous effusions all were males, with age ranged from 17 to 72 years with a mean age of $39.4 \pm 12$ years.

According to Table 2, The mean CEA level in carcinomatous pleural effusion was $267.33 \mathrm{ng} / \mathrm{ml}$, and it was significantly $(\mathrm{p}<0.0287)$ higher than tuberculous effusion with $1.28 \mathrm{ng} / \mathrm{ml}$. CEA values above $8 \mathrm{ng} / \mathrm{ml}$ were found in 24 out of $33(72 \%)$ carcinomatous effusions and in none of the tuberculous effusions. There was a significant difference between these two figures with $\mathrm{p}$ value 0.000048 .

The mean CA 15-3 level in carcinomatous effusion was $47.19 \mathrm{U} / \mathrm{ml}$ which was not significantly $(\mathrm{p}>0.414)$ higher than that in tuberculous effusions with $32.58 \mathrm{U} / \mathrm{ml}$. CA $15-3$ values above $42 \mathrm{U} / \mathrm{ml}$ were found in 14 out of $33(42 \%)$ of carcinomatous effusions and in three out of ten tuberculous effusion (30\%). The difference between these two groups was not significant with $\mathrm{p}$ value 0.257 .

Among the above two markers, there was a significant correlation between CEA levels in carcinomatous and tuberculous pleural effusions. No such correlation was observed with CA 15-3 levels.

CEA alone has a relatively high sensitivity of $100 \%$ ( $95 \%$; confidence interval of 0.85 to 1.00 ) when compared to CA $15-3$, which has a sensitivity of $52 \%$ ( $95 \%$; confidence interval of 0.33 to 0.53$)$

\section{DISCUSSION}

Niwa Y, Kishimoto $\mathrm{H}$ et al [7] measured the concentration of CEA in the pleural fluid and sera from cancer patients and control patients with tuberculosis, they observed that CEA concentration in the pleural fluid and sera from carcinoma lung was higher than those of tuberculous pleurisy with a sensitivity of $60 \%$ and specificity of $74 \%$.

Villena et al [8] studied the diagnostic value of CEA, CA 15-3, CA 72-4 assay in pleural fluid of 207 carcinoma lung patients. The combination of CEA, CA 15-3 plus CA 72-4 yielded the best accuracy with sensitivity of $\& * \%$ and specificity of $95 \%$. Conclusion from the study was the assay of these markers was useful in differentiating between pleural effusion of malignant and benign origin.

In a similar study done by Hackner $\mathrm{K}^{(13)}$, it was noted that by using receiver operating characteristics analysis, at the cut-off of 1.0 , the CEA ratio showed a specificity of $92 \%$ and sensitivity of $85 \%$, with a positive predictive value of $91 \%$ and a negative predictive value of $87 \%$. These results are higher than in previous investigations on different pleural tumour markers and their combination. Considering these findings, they concluded that the CEA ratio is a useful tool in predicting pleural carcinosis. Elevated results in cytology-negative patients should lead to further investigations, such as repeated cytological examination or thoracoscopy. 
However, in a larger study done by Yuan Yang et al ${ }^{(14)}$, For pleural fluid tumor marker combinations including more than 3 studies, the summary estimates of the sensitivity/specificity for diagnosing MPE were as follows: CEA + CA 125, 0.65/0.98; CEA + CA 15-3, 0.64/0.98; CEA + CA 19-9, 0.58/0.98; CEA + CYFRA 21-1, 0.82/0.92; and CA 15-3 + CYFRA 21-1, 0.88/0.94. Hence concluded that in patients with undiagnosed pleural effusion, the combinations of positive pleural CEA + CA 15-3 and CEA + CA 19-9 are highly suspicious for pleural malignancy, but the sensitivity of these tests is low.

Our study also revealed increased CEA levels in carcinomatous effusions, that positive in $72 \%$ of carcinomatous effusion and none of the tuberculous effusions. However CA $15-3$ positive in $42 \%$ of carcinomatous effusions and $30 \%$ of tuberculous effusions. Based on this high sensitivity and specificity CEA may be useful in differentiating carcinomatous effusion from tuberculous effusions.

Zhai $\mathrm{K}$ et $\mathrm{al}^{(12)}$ found that the levels of four tumour markers were significantly higher in MPE than in BPE and the corresponding serum. The concentrations of CEA and CA 15-3 were more stable than the concentrations of CA 125 and CA 19-9. CEA was the best single marker for discriminating MPE from BPE. With a specificity of $100 \%$ in the total population, the highest sensitivity $(37.8 \%)$ using serum was found in CEA. In addition, CEA presented $19.8 \%$ sensitivity in PE and $18.0 \%$ sensitivity in the $\Delta(\mathrm{PE}-$ serum $)$. For CA $15-3$, the sensitivity was $32.4 \%$ in $\mathrm{PE}, 15.3 \%$ in the $\mathrm{PE} / \mathrm{serum}$ ratio and $25.2 \%$ in the $\Delta(\mathrm{PE}-$ serum $)$.

Based on these observations, Zhai $\mathrm{K}$ et al ${ }^{(12)}$ concluded that CEA and CA 15-3 rather than CA 125 and CA 19-9 are more reliable to differentiate between MPE and BPE. The use of the $\triangle(\mathrm{PE}-$-serum $)$ value in TMs, such as CEA and CA 15-3, may improve the sensitivity and specificity of the diagnosis etiology of PE.

Since anti CEA sera used for determination of CEA cross react with CEA associated antigen, such as non specific cross reacting antigen [9] and normal fecal antigen [10] and increase in CEA levels is not specific for carcinoma in other reported cases .[11] In our series none of the tuberculous effusion had a CEA content over $10 \mathrm{ng} / \mathrm{ml}$. This may be ascribed to the difference of the method for determining CEA. Although the etiologies of exudative pleural effusions are diverse, we conclude that combined assays of CEA and CA 15-3 are useful in differentiating carcinomatous effusions from tuberculous effusions.

\section{Legend for Tables}

Table1: Showing incidence of positive tumor markers in study samples

Table 2: Showing the results of the study

\section{Table 1: Showing incidence of positive tumor markers in study} samples

\begin{tabular}{|c|c|c|}
\hline Effusions & CEA & CA 15-3 \\
\hline Carcinomatous & $24 / 33$ & $14 / 33$ \\
\hline Tuberculous & $0 / 10$ & $3 / 10$ \\
\hline
\end{tabular}

Table 2: Showing the results of the study

\begin{tabular}{|c|c|c|c|}
\hline Tumor marker & $\begin{array}{c}\text { Malignant } \\
\text { effusion }\end{array}$ & $\begin{array}{c}\text { Tuberculous } \\
\text { effusion }\end{array}$ & P value \\
\hline Mean CEA & $267.33 \mathrm{ng} / \mathrm{ml}$ & $1.29 \mathrm{ng} / \mathrm{ml}$ & $\begin{array}{c}0.0287 \\
\text { Significant }\end{array}$ \\
\hline Mean CA 15-3 & $49.17 \mathrm{U} / \mathrm{ml}$ & $32.58 \mathrm{ng} . \mathrm{ml}$ & $\begin{array}{c}0.414 \\
\text { significant }\end{array}$ \\
\hline CEA $>8 \mathrm{ng} / \mathrm{ml}$ & $72 \%$ & Nil & $\begin{array}{c}0.000048 \\
\text { Significant }\end{array}$ \\
\hline $\begin{array}{c}\mathrm{CA} 15-3>42 \\
\mathrm{U} / \mathrm{ml}\end{array}$ & $42 \%$ & $37.7 \%$ & $\begin{array}{c}0.257 \\
\text { significant }\end{array}$ \\
\hline
\end{tabular}

\section{ACKNOWLEDGEMENTS}

Our sincere thanks to the staff of the Government General and Chest Hospital for their support during the study.

Dr. Subhakar Kandi is Professor of Pulmonary Medicine in Osmania Medical College, Hyderabad, India and NTEP task force chairman, South Zone India.

\section{REFERENCES}

1. Udaya BS, Prakash MD, Reiman HN. Comparison of needle biopsy with cytological analysis for the evaluation of pleural effusion: analysis of 414 cases. Mayo Clin Proc

\section{5; 60: 158-164}

2. Ryan CJ, Rodgers RF, Unni KK, Hepper NGG. The outcome of patients with pleural effusion of indeterminate cause at thoracotomy. Mayo Clin Proc 1981; 56: 145-149.

3. Nystron JS, Dyceb, Wada J, Baterman JR carcinoembrionic antigen titres on effusion fluid. Arch Intern Med 1977: 137:875-9.

4. Fietcher RH carcinoembrionic antigen. Annu Intern Med 1986: 104: 66-73.

5. Hayes Df, Pusson Betal, Comparision of circulating CA 15-3 and CEA levels in patients with breast cancer. J. Clin Oncol 1986: 4: 1542-1550

6. Gion M, Fasan S, Pallini A, Evaluation of CA 15-3 serum levels in breast cancer patients. Eur. J. Cancer 1990: 26: 577-80

7. Niwa Y, Kishimoto H, Shimokata K, carcinomatous and tuberculous pleural effusions comparison of tumor markers. Chest 1985; 87; 351-5.

8. Victoria villena, angel lopez, Juana Alfaro, Diagnostic value of CA 72-4, CEA, CA 15-3 and CA 19-9 assay in pleural fluid. Cancer 1996; 78:736-40.

9. Von Kleist S, Chavanel G, Burtin P. Identification of an antigen from normal human tissue that cross reacts with the carcinoembryonic antigen. Proc Natl Acad Sci USA 1972; 69:2492-4.

10. Stanford CF, Neville AM, Laurence DJR. Concurrent assays of plasma and pleural effusion levels of carcinoembryonic antigen in the diagnosis of pulmonary disease. Lancet 1978; 2:53.

11. Maritz FJ, Malan C, Le Roux I, Adenosine deaminase estimations in the differentiation of pleural effusions. S. Afr Med 1982; 62: 556-8.

12. Zhai K, Wang W, Wang Y, Liu JY, Zhou Q, Shi HZ. Diagnostic accuracy of tumor markers for malignant pleural effusion: a derivation and validation study. J Thorac Dis 2017;9(12):5220-5229. doi: 10.21037/jtd.2017.11.62

13. Hackner K, Errhalt P, Handzhiev S. Ratio of carcinoembryonic antigen in pleural fluid and serum for the diagnosis of malignant pleural effusion. Ther Adv Med Oncol. 2019;11:1758835919850341.

14. Yuan Yang, Ya-Lan Liu, Huan-Zhong Shi Diagnostic Accuracy of Combinations of Tumor Markers for Malignant Pleural Effusion: An Updated Meta-Analysis Respiration
2017;94:62-69 